\title{
EFFICACY OF LASER TREATMENT FOR LINGUAL FRENECTOMY
}

\author{
Applicant: Kenji Yoshida, DDS., Ph.D \\ Department of Oral and Maxillofacial Surgery, \\ School of Dentistry, Aichi-Gakuin University
}

\section{Background and Aims}

Ankyloglossia causes speech disturbance due to incomplete tongue mobility. To treat ankylosis of the lingual frenulum, a lingual frenectomy is performed. However, because of the abundance of blood vessels in the oral region, care must be taken about postoperative bleeding from the operative wound, when surgery is performed using the conventional surgical scalpel. On the other hand, when an appropriate surgical laser is used to make the incision, such as the Nd:YAG, $\mathrm{CO} 2$, diode, $\mathrm{KTP} / 532$, Er:YAG laser and so on, it is possible to reduce the bleeding during incision of oral soft tissue. This report presents the efficacy of the surgical laser for lingual frenectomy.

\section{Subjects and Methods}

The subjects were 15 patients with ankylosis of the lingual frenulum on whom laser frenectomy was performed. Two cases were carried out with the $\mathrm{CO}_{2}$ laser, five cases with the diode laser and eight cases with the Nd:YAG laser, used at the parameters shown in Table 1.

Table 1: Lasers and parameters used for lingual frenectomy

\begin{tabular}{|c|c|c|c|c|c|c|}
\hline Laser & $\begin{array}{c}\text { Model } \\
\text { (Manufacturer) }\end{array}$ & $\lambda(n m)$ & Temporal mode & Output power & $\begin{array}{c}\text { 1.Spot size } \\
\text { 2.Tip diameter } \\
\text { 3.Fiber diameter } \\
\text { ( } \mathrm{mm})\end{array}$ & $\begin{array}{l}\text { Irradiation } \\
\text { time }(s)\end{array}$ \\
\hline $\mathrm{CO}_{2}$ & $\begin{array}{l}\text { LX-20 } \\
\text { (Luxar Corp, USA) }\end{array}$ & $10,600 \mathrm{~nm}$ & $\mathrm{CW} /$ superpulsed & $8 \mathrm{~W}$ & 1.Spot size $0.4 \mathrm{~mm}$ & 4 \\
\hline Nd:YAG & $\begin{array}{l}\text { CL-X } \\
\text { (SLT, Japan) }\end{array}$ & $1,064 \mathrm{~nm}$ & $\mathrm{CW}$ & $11 \mathrm{~W}$ & $\begin{array}{l}\text { 2. Tip diameter of } \\
\text { surgical rod } 0.2 \mathrm{~mm}\end{array}$ & 5 \\
\hline Diode & $\begin{array}{l}\text { OSL3000 } \\
\text { (Osada Inc, Japan) }\end{array}$ & $810 \pm 20 \mathrm{~nm}$ & CW & $2 \mathrm{~W}$ & 3.Fiberdiameter $600 \mu \mathrm{m}$ & 5 \\
\hline
\end{tabular}

$\lambda=$ wavelength, $\mathrm{CW}=$ continuous wave

\section{Addressee for Correspondence:}

Kenji Yoshida DDS

Department of Oral and Maxillofacial Surgery, School of Dentistry, Aichi-Gakuin University

2-11 Suemori-dori, Chikusa-ku, Nagoya 464-8651 JAPAN

Tel: +81-52-759-2182 / Fax: +81-52-759-2157

E-mail: kenji@dpc.aichi-gakuin.ac.jp
Before surgery, a local anesthetic (2\% Lidocaine with 1/80,000 epinephrine) was infiltrated around the lingual frenulum. Frenectomy was then carried out with the laser of choice. The incision was made cleanly Manuscript received: July 16th, 2010 Accepted for publication: August 20th, 2010 


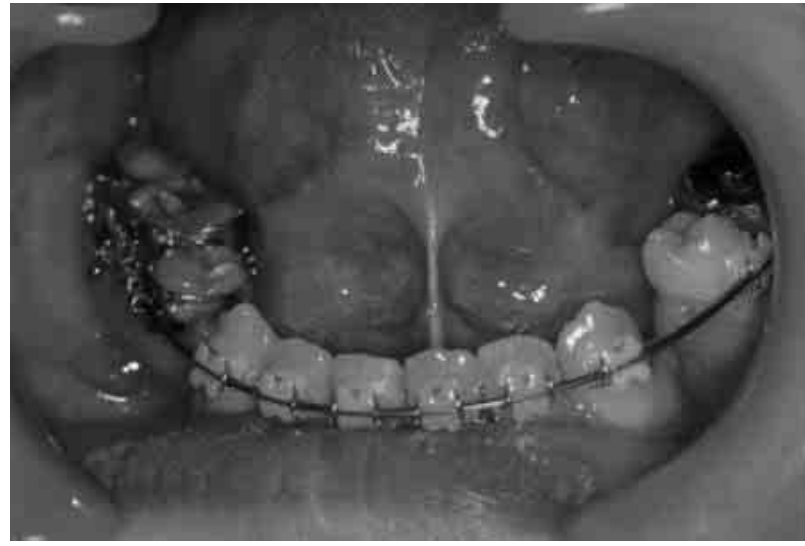

Fig.1 Ankyloglossia can be observed and insufficient tongue mobility.

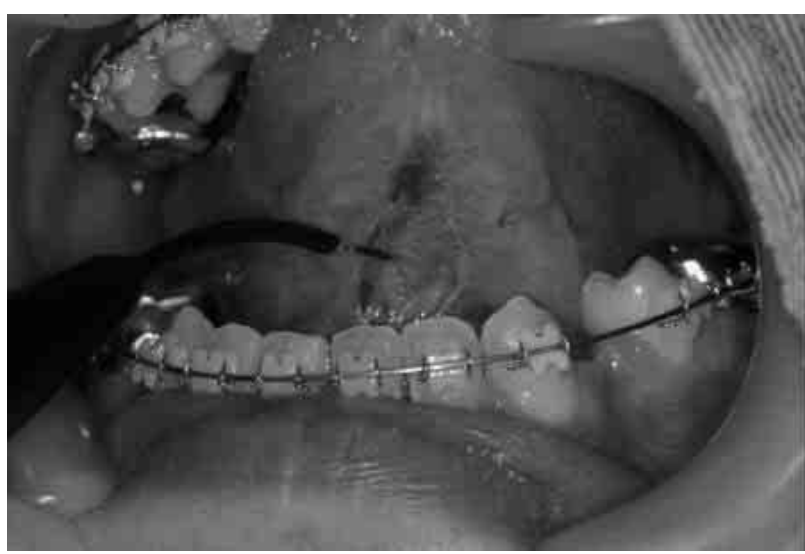

Fig.3 The operation is performed easily and quickly.

with minimized bleeding due to the photothermal cauterizing action of the focused laser beam. The wound was sutured to avoid delayed postoperative bleeding. Neither postoperative edema nor pain was noted, infection was not seen, and wound healing was not delayed.

\section{Representative Case Report}

A 19-year-old male patient was referred for frenectomy by his orthodontist. The patient's tongue mobility was limited and it was almost impossible to raise the tongue upward (Fig.1). Before the operation, local anesthesia (2\% Lidocaine with 1/80,000 Epinephrine) was performed around the lingual frenulum, and the frenectomy was performed using the diode laser described above. The incision was made with the tip of the $600 \mu \mathrm{m}$ optical fiber in contact with the tissue, incident power of $2 \mathrm{~W}, \mathrm{CW}$. Incision was facilitated by pulling the tip of the tongue upwards to apply tension to the frenulum, and the operation was performed very

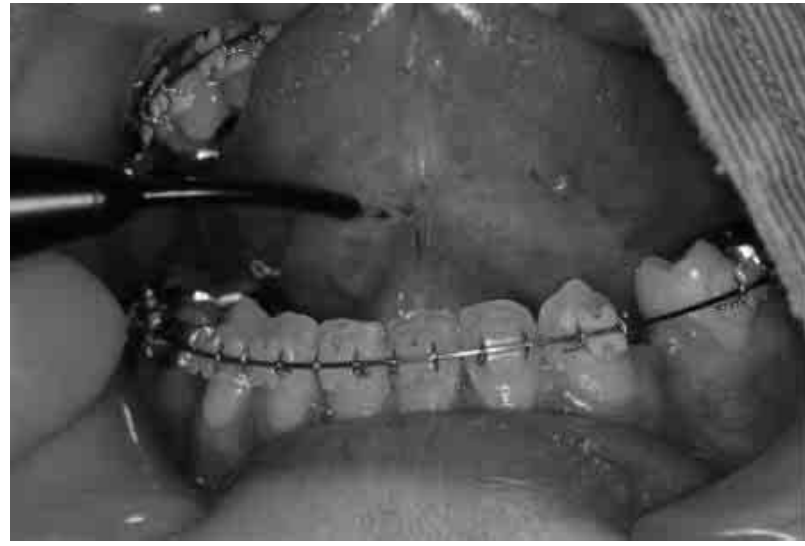

Fig.2 The incision is made with the tip of the optical fiber of the diode laser.

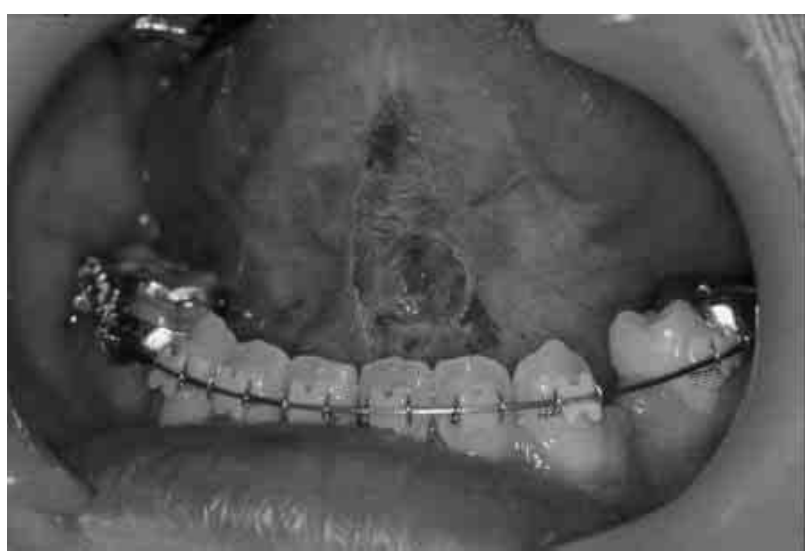

Fig.4 The incised surfaces are clear with no bleeding.

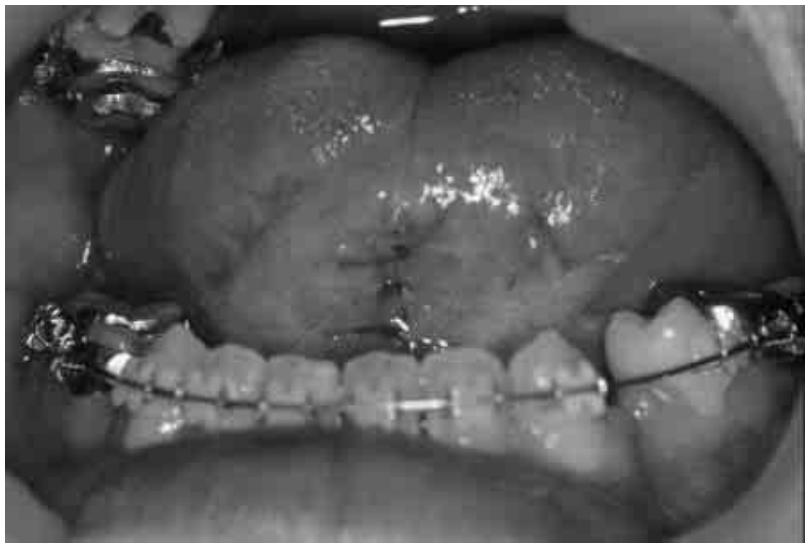

Fig.5 The wound is sutured closed.

swiftly (Fig.2). Following the frenectomy, tension on the tongue was released and the tongue mobility had sufficiently increased, with a smooth action (Figs.3,4). The incised wound was sutured closed to avoid the risk of delayed postoperative haemorrhage because the blood vessels in the sublingual region lie deep in the muscle (Fig.5). 


\section{ILLiS CASE REPORT}

\section{Results}

In all cases, laser lingual frenectomy was performed without any problems. The postoperative course was excellent and trouble-free. After the operation the related oral function improved in all cases.

\section{Conclusions}

Ankyloglossia sometimes causes problems such as speech disturbance and trouble with oral hygiene, eating and other related functions due to the restriction of the tongue movement. Decision making regarding a frenectomy is in general reached in consultation with a speech therapist. Because the lingual frenectomy is usually discussed when the patients are in their childhood, the surgical technique is minimally invasive, and the laser lingual frenectomy is an excellent and elegant solution. Many kinds of laser devices for oral and dental use have been recently developed, and applications of the laser in clinical dental practice are spreading in the field of dentistry. However, at the same time, because of the various potential hazards associated with the surgical laser, the clinician must consider all aspects of clinical safety to prevent any laser-related accidents occurring in at the narrow operative field of the oral cavity. 